\title{
RESEARCH OF THE INFLUENCE OF EXTERNAL FACTORS ON THE Measurement of a Basic Soil Quality Parameter
}

\author{
Tsvetelina Georgieva, Sechkin Remzi, Nadezhda Paskova, Emil Stefanov, \\ Nikolaos Sigrimis \& Plamen Daskalov
}
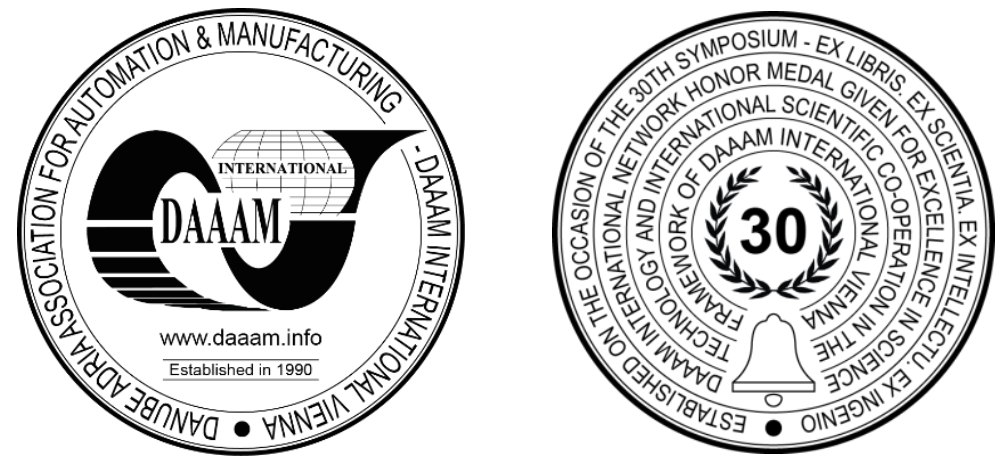

This Publication has to be referred as: Georgieva, T[svetelina]; Remzi, S[echkin]; Paskova, N[adezhda]; Stefanov, E[mil]; Sigrimis, N[ikolaos] \& Daskalov, P[lamen] I[vanov] (2019). Reasearch of the Influence of External Factors on the Measurement of a Basic Soil Quality Parameter, Proceedings of the 30th DAAAM International Symposium, pp.10971101, B. Katalinic (Ed.), Published by DAAAM International, ISBN 978-3-902734-22-8, ISSN 1726-9679, Vienna, Austria

DOI: $10.2507 / 30$ th.daaam.proceedings.153

\begin{abstract}
The paper presents a research of the influence of external factors on the measurement of a basic soil quality parameter. Developed system based on Arduino platform is used for measurement of basic soil parameter acidity. Research of the influence of temperature and soil type on the measurement of soil acidity is carried out. The system has been experimentally tested with soil samples from two main types of soil in Bulgaria. The results for the soil parameters obtained with the Arduino based system are compared with a reference measuring instrument. The presented Arduino based system for soil parameters measurements shows good measurement accuracy sufficient for engineering research.
\end{abstract}

Keywords: Soil Acidity; Arduino platform; Reference measurement.

\section{Introduction}

There are different types of soil quality analysis systems. Systems based on different soil analysis methods are presented. Spectral analysis offers many possibilities in soil analysis. It can detect the presence of very small quantities (10-11-10-12g) of an element. The intensity of the emitted spectral lines makes it possible to determine the amount of the element (quantitative spectral analysis). In recent years, experts have highlighted the benefits of spectral analysis in the infrared region as a quick alternative to simultaneously investigating several indicators. The development of instruments, and in particular the ability to use optical fiber instruments, allows samples to be analyzed not only in specialized laboratories but also in the field [1].

The $\mathrm{pH}$, content of organic carbon, content of absorbable forms of phosphorus and potassium can be determined. The InfraAlyzer450, Technicon is a filter spectrophotometer equipped with 19 fixed filters, allowing spectral data to be obtained at 19 wavelengths ranging from 1445 to 2348nm. FQA-NIRGun, Fantec, is a scanning spectrophotometer operating in the shortwave range of 600 to $1100 \mathrm{~nm}$. In both spectral apparatus, the sample spectrum is obtained by measuring the diffuse reflection from ground and homogenized samples and recorded as $\log (1 / \mathrm{R})$, where $\mathrm{R}$ is the reflection from the sample. The Technicon InfraAlyzer System Software quantitative analysis software is used to process 
the spectral data obtained with the InfraAlyzer450 and the Unscrambler software package, Camo AD, for the FQANIRGun data package. The disadvantage of the device is its high cost.

In addition to digital $\mathrm{pH}$ meters, there are digital soil moisture meters. They help farmers effectively manage irrigation schedules. One such solution has two probes: one for soil moisture and one drill for temperature. The latter is used for automatic temperature compensation. It can also be used alone as a thermometer to measure soil temperature or to measure the temperature of fruits and other foodstuffs. Offers digital soil moisture measurement, measuring range from 0 to $100 \mathrm{U}$, solid stainless steel $6 \mathrm{~mm}$ diameter probe and $220 \mathrm{~mm}$ length, drilled metal probe, temperature sensor for temperature measurement from $-50{ }^{\circ} \mathrm{C}$ to $+200^{\circ} \mathrm{C}$, power supply with $9 \mathrm{~V}$ battery [2],[3].

A soil analyzer is also available that combines a hygrometer, a light meter and a pH meter. It measures the $\mathrm{pH}$ of the soil and the absorption of nutrients and mineral fertilizers by acidity. It measures moisture in the root system and prevents the risk of overfilling or drying of the plant. No battery required, simple and easy to use. Just put the tester in the soil to go to the setting to be measured and read on the scale. Moisture is displayed on the ten-point system from 0 (dry) to 10 (wet). The $\mathrm{pH}$ is displayed on a conventional $\mathrm{pH}$ scale, ranging from 3.5 (acidic) to 8 (alkaline) [4],[5].

The analysis of the existing soil analyzers shows that it is necessary to develop a low-cost device that allows indirect measurement of the basic chemical elements of the soil by measuring the basic parameters of the soil, giving information about its condition. This device need to be assess from influence of the external factors during measurements.

The paper presents a research of the influence of external factors on the measurement of a basic soil quality parameter. The system is implemented by selecting suitable devices to measure the quantities and transmit and record the information based on Arduino platform. The software of the controller and a graphical user mobile applications interface have been developed for system setup, visualization and processing of the collected data. The future research will be focus on accuracy assessment of this system with traditional reference devices in real conditions.

\section{Research of the influence of external factors on the measurement of basic soil quality parameter}

\subsection{Soil samples}

The spatial combinations of relief, climate and vegetation are of paramount importance for the horizontal and vertical arrangement of the main soil types and for the formation of soil zones [6]. The soil cover is represented by 15 soil types, in which 42 subtypes are divided. Within the scope of the North Bulgarian forest-steppe soil zone, zonal soil types are distributed - black earths / 54\% of the area of the zone / and gray forest soils / 39\% of the area of the zone /.

Black Earth soils are widespread in the Danube Plain (western and central part), the Southern Plateau Plateau and the Ludogorie. They are attached to the plain-hilly terrain of the plain and loess cover, and the dry temperate-continental climate and dry-loving vegetation. They are characterized by increased humus horizon power $(60-80 \mathrm{~cm})$ but low humus content $(2-4 \%)$. They are divided into: carbonate, typical, leached and degraded.

Yellow-podzolic soils are distributed mainly along the left bank of the Veleka River. They are formed under humid transitional-Mediterranean climatic conditions and with wide participation of deciduous vegetation of the Colchid-Pontic type. The soil-forming rocks are highly crushed and deeply weathered with shales, sandstones and litters of Jurassic and Cretaceous age. They are distinguished by their characteristic yellow color (due to the presence of limonites), high power of the soil horizon $(80-100 \mathrm{~cm})$, insignificant humus horizon $(15 \mathrm{~cm})$ and a great variety in mechanical composition.

The diverse conditions of soil formation in Bulgaria have led to the formation of soils with different fertility and agrotechnical qualities. The most common types of soil types are cinnamon forest soils (29\% of the country's territory), followed by black earth soils / $23 \%$ of the country's area /. Gray forest soils occupy about $17 \%$, brown forest soils - $15 \%$, alluvial-meadow soils - 7\%, tarp - $6 \%$ of the country's area.

In the research are used samples from Black Earth soils and Yellow-podzolic soils.

\subsection{Microprocessor system for measurement of basic quality soil parameters}

Developed system for measurement of main soil quality parameters, require using the following sensors - for electrical conductivity, for moisture and $\mathrm{pH}$. Main parts of the system are microcontroller and xbee module. Main microcontroller (figure 1a) is widely used open-source microcontroller board based on the ATmega328P microcontroller and developed by Arduino.cc [7]. The board is equipped with sets of digital and analog input/output (I/O) pins that may be interfaced to various expansion boards (shields) and other circuits. The board features 14 digital pins and 6 analog pins. It is programmable with the Arduino IDE (Integrated Development Environment) via a type B USB cable. It can be powered by a USB cable or by an external 9 volt battery, though it accepts voltages between 7 and 20 volts. The Xbee shield allows an Arduino board to communicate wirelessly using Zigbee. It is based on the Xbee module from MaxStream. The module can communicate up to 100 feet indoors or 300 feet outdoors (with line-of-sight). It can be used as a serial/usb replacement or you can put it into a command mode and configure it for a variety of broadcast and mesh networking options. 


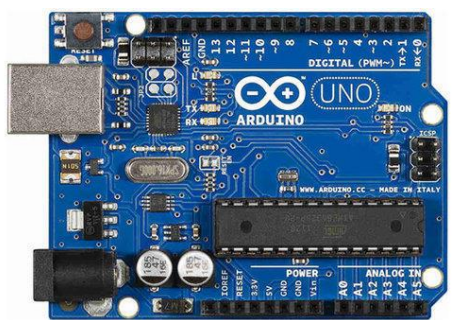

a)

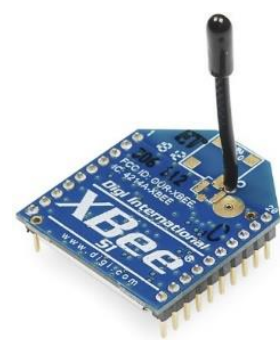

b)

Fig. 1. Arduino microcontroller and Xbee wireless module.

The sensors for measuring the main parameters of the soil ( $\mathrm{pH}$, electrical conductivity and humidity) are mainly used in the field of precision farming. Appropriate sensors are shown on figure 2. Their output signals are compatible with the analogue/digital inputs of the transmitter module. The sensors are pre-calibrated with calibration solutions for $\mathrm{pH}$ and electrical conductivity with accurate values.

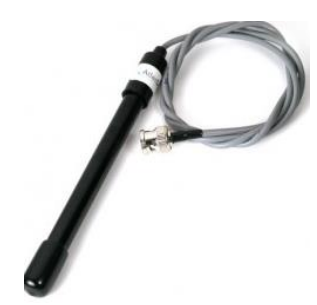

a)

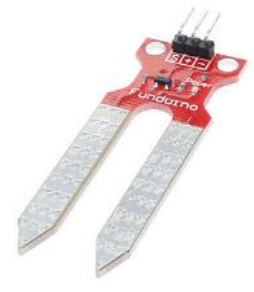

b)

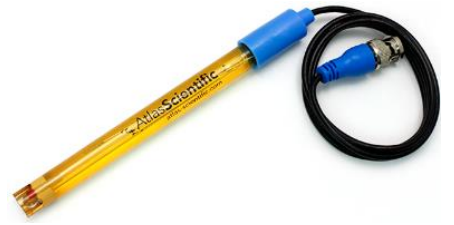

c)

Fig. 2. Sensors for measuring basic soil parameters: a) electrical conductivity, b) humidity, c) acidity.

Developed wireless system for soil indicators measurement is shown on figure 3. For real measurement is need user to know which external factors influence to the measurements of the system.

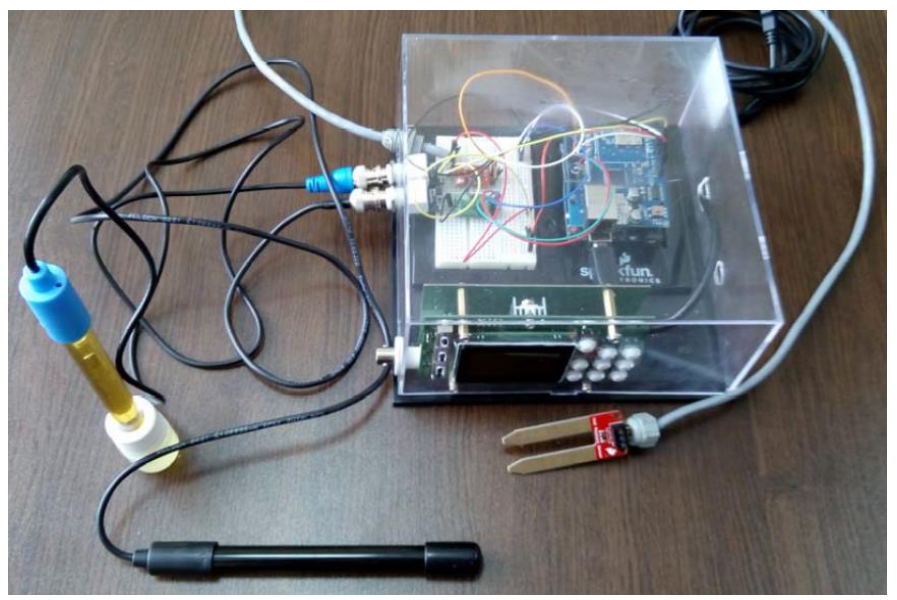

Fig. 3. Wireless system for soil indicators measurement

\subsection{Reference device for soil pH measurement}

For reference device is used a pH measurement device with analogue sensor. The values are measurement manually.

\subsection{Experiment description}

The soil sample preliminary is prepared. Three kind of soil samples are measured. The first one is with temperature around 18 degrees, the second one is with temperature -24 degrees and the third one -35 degrees. The samples are measured with developed system and standard device and the results for soil $\mathrm{pH}$ indicator are saved in database for calculation the error between obtained data. 


\section{Results}

For the purpose of measurement, two types of soils taken from different locations are used. The depth of the soil sample is $0-30 \mathrm{~cm}$ deep. Table 1 presents the measured $\mathrm{pH}$ values of the soil samples taken. The samples were first measured with standard device for measuring $\mathrm{pH}$ and then with developed wireless system for measuring $\mathrm{pH}$ with Arduino sensors. Absolute and percentage relative errors are calculated [8]:

- Calculation of absolute error

$\Delta(\mathrm{pH})=\left|\mathrm{pH}_{\mathrm{sys}}-\mathrm{pH}_{\mathrm{ref}}\right|$

- Calculation of percentage relative error

$\delta(\mathrm{pH})=\frac{\Delta(\mathrm{pH})}{\mathrm{pH}_{\text {sys }}} x 100, \%$

Table 1 and table 2 show the results from measurement of soil $\mathrm{pH}$ values with developed system and reference device, as well as calculated errors.

\begin{tabular}{|c|c|c|c|c|}
\hline T1 & 18,24 & & & \\
\hline & pHsys & pHref & $\begin{array}{c}\text { Absolute } \\
\text { Error }\end{array}$ & $\begin{array}{l}\text { Relative } \\
\text { Error, \% }\end{array}$ \\
\hline 1 & 6,07 & \multirow{10}{*}{6,8} & 0,73 & 12,03 \\
\hline 2 & 6,02 & & 0,78 & 12,96 \\
\hline 3 & 5,96 & & 0,84 & 14,09 \\
\hline 4 & 5,94 & & 0,86 & 14,48 \\
\hline 5 & 5,95 & & 0,85 & 14,29 \\
\hline 6 & 5,93 & & 0,87 & 14,67 \\
\hline 7 & 5,9 & & 0,90 & 15,25 \\
\hline 8 & 6,11 & & 0,69 & 11,29 \\
\hline 9 & 6,16 & & 0,64 & 10,39 \\
\hline 10 & 6,11 & & 0,69 & 11,29 \\
\hline
\end{tabular}

\begin{tabular}{|c|c|c|c|c|}
\hline T2 & 24,04 & & & \\
\hline & pHsys & pHref & $\begin{array}{c}\text { Absolute } \\
\text { Error }\end{array}$ & $\begin{array}{l}\text { Relativg } \\
\text { Error, }\end{array}$ \\
\hline 1 & 6,69 & \multirow{10}{*}{6,9} & 0,21 & 3,08 \\
\hline 2 & 6,64 & & 0,26 & 3,87 \\
\hline 3 & 6,63 & & 0,27 & 4,10 \\
\hline 4 & 7,10 & & 0,20 & 2,82 \\
\hline 5 & 7,20 & & 0,30 & 4,17 \\
\hline 6 & 7,20 & & 0,30 & 4,17 \\
\hline 7 & 7,15 & & 0,25 & 3,50 \\
\hline 8 & 7,25 & & 0,35 & 4,83 \\
\hline 9 & 7,18 & & 0,28 & 3,90 \\
\hline 10 & 6,83 & & 0,07 & 1,02 \\
\hline
\end{tabular}

\begin{tabular}{|c|c|c|c|c|}
\hline T3 & 35,5 & & & \\
\hline & pHsys & pHref & $\begin{array}{c}\text { Absolute } \\
\text { Error }\end{array}$ & $\begin{array}{l}\text { Relative } \\
\text { Error, \% }\end{array}$ \\
\hline 1 & 6,63 & \multirow{10}{*}{6,6} & 0,03 & 0,45 \\
\hline 2 & 6,63 & & 0,03 & 0,45 \\
\hline 3 & 6,55 & & 0,05 & 0,76 \\
\hline 4 & 6,48 & & 0,12 & 1,85 \\
\hline 5 & 6,46 & & 0,14 & 2,17 \\
\hline 6 & 6,45 & & 0,15 & 2,33 \\
\hline 7 & 6,45 & & 0,15 & 2,33 \\
\hline 8 & 6,43 & & 0,17 & 2,64 \\
\hline 9 & 6,41 & & 0,19 & 2,96 \\
\hline 10 & 6,36 & & 0,24 & 3,77 \\
\hline
\end{tabular}

Table 1. $\mathrm{pH}$ values for Black Earth soil

\begin{tabular}{|c|c|c|c|c|}
\hline $\mathrm{T3}$ & 15,73 & & & \\
\hline & pHsys & pHref & $\begin{array}{c}\text { Absolute } \\
\text { Error }\end{array}$ & $\begin{array}{l}\text { Relative } \\
\text { Error,\% }\end{array}$ \\
\hline 1 & 6,79 & \multirow{10}{*}{7} & 0,21 & 3,09 \\
\hline 2 & 6,76 & & 0,24 & 3,55 \\
\hline 3 & 6,59 & & 0,41 & 6,22 \\
\hline 4 & 6,35 & & 0,65 & 10,24 \\
\hline 5 & 6,2 & & 0,8 & 12,90 \\
\hline 6 & 6,18 & & 0,82 & 13,27 \\
\hline 7 & 6 & & 1 & 16,67 \\
\hline 8 & 5,97 & & 1,03 & 17,25 \\
\hline 9 & 5,86 & & 1,14 & 19,45 \\
\hline 10 & 5,82 & & 1,18 & 20,27 \\
\hline
\end{tabular}

\begin{tabular}{|c|c|c|c|c|}
\hline T1 & 24,75 & & & \\
\hline & pHsys & pHref & $\begin{array}{c}\text { Absolute } \\
\text { Error }\end{array}$ & $\begin{array}{l}\text { Relative } \\
\text { Error,\% }\end{array}$ \\
\hline 1 & 6,64 & \multirow{10}{*}{6,9} & 0,26 & 3,92 \\
\hline 2 & 6,64 & & 0,26 & 3,92 \\
\hline 3 & 6,74 & & 0,16 & 2,37 \\
\hline 4 & 6,85 & & 0,05 & 0,73 \\
\hline 5 & 6,93 & & 0,03 & 0,43 \\
\hline 6 & 6,93 & & 0,03 & 0,43 \\
\hline 7 & 7,07 & & 0,17 & 2,40 \\
\hline 8 & 7,05 & & 0,15 & 2,13 \\
\hline 9 & 7,03 & & 0,13 & 1,85 \\
\hline 10 & 7,01 & & 0,11 & 1,57 \\
\hline
\end{tabular}

\begin{tabular}{|c|c|c|c|c|}
\hline T2 & 34,73 & & & \\
\hline & pHsys & pHref & $\begin{array}{l}\text { Absolute } \\
\text { Error }\end{array}$ & $\begin{array}{l}\text { Relative } \\
\text { Error,\% }\end{array}$ \\
\hline 1 & 6,74 & \multirow{10}{*}{7} & 0,26 & 3,86 \\
\hline 2 & 6,67 & & 0,33 & 4,95 \\
\hline 3 & 6,65 & & 0,35 & 5,26 \\
\hline 4 & 6,7 & & 0,3 & 4,48 \\
\hline 5 & 6,62 & & 0,38 & 5,74 \\
\hline 6 & 6,57 & & 0,43 & 6,54 \\
\hline 7 & 6,56 & & 0,44 & 6,71 \\
\hline 8 & 6,52 & & 0,48 & 7,36 \\
\hline 9 & 6,51 & & 0,49 & 7,53 \\
\hline 10 & 6,5 & & 0,5 & 7,69 \\
\hline
\end{tabular}

Table 2. $\mathrm{pH}$ values for Yellow-podzolic soils

\section{Conclusion}

The analysis of the existing soil analyzers shows that it is necessary to develop a low-cost device that allows indirect measurement of the basic chemical elements of the soil by measuring the basic parameters of the soil, giving information about its condition. This device need to be assess from influence of the external factors during measurements. A wireless microprocessor system based on ATmega328P microcontroller and Arduino sensors for measurement of soil properties is developed. Main quality indicator of soil $\mathrm{pH}$ of two types of soils taken from different places in Bulgaria are measured. The developed wireless system is compared with standard reference device and percentage relative errors are calculated. The measurement error for $\mathrm{pH}$ is from $0.03 \%$ to $1.18 \%$. The relative errors for the variation of $\mathrm{pH}$ obtained for all soil samples are lower than the maximum allowable. This is an indicator for the effectiveness of the developed wireless system for measurement of quality soil indicators. Although the variation in the relative error values the system applies an adequate measurement of soil $\mathrm{pH}$ for precise agriculture. In the future using more frequent calibration and temperature compensation will improve measurement and decrease the errors when external factors influence to the measurement.

\section{Acknowledgments}

The study was supported by contract of University of Ruse “Angel Kanchev”, № BG05M2OP001-2.009-0011-C01, " Support for the development of human resources for research and innovation at the University of Ruse "Angel Kanchev". 
The project is funded with support from the Operational Program " Science and Education for Smart Growth 2014 - 2020 " financed by the European Social Fund of the European Union.

The research is supported by a contract with Ruse University "Angel Kanchev" under NSF - 2019 - EEA - 04 , "Research of the influence of external factors on the accuracy of basic soil parameters measurement with a low-cost microprocessor system".

\section{References}

[1] Zhanga, Y.; Biswasa, A. \& Viacheslav, I. (2017). Adamchukc Implementation of a sigmoid depth function to describe change of soil $\mathrm{pH}$ with depth, Geoderma, Vol. 289, 1-10

[2] Fan, K.; Weisenhorn, P.; Gilbert, J.; Shi, Y.; Baif, Y. \& Chu, H. (2018). Soil pH correlates with the co-occurrence and assemblage process of diazotrophic communities in rhizosphere and bulk soils of wheat fields, Soil Biology and Biochemistry, Vol. 121, 185-192

[3] Bravoa, S.; Amorósa, B.; Pérez-de-los-Reyesa, B.; Garcíaa, F.; Morenoa, M,; Sánchez-Ormeñoa, M. \& Higuerasb, $\mathrm{P}$. (2017). Influence of the soil $\mathrm{pH}$ in the uptake and bioaccumulation of heavy metals ( $\mathrm{Fe}, \mathrm{Zn}, \mathrm{Cu}, \mathrm{Pb}$ and $\mathrm{Mn})$ and other elements $(\mathrm{Ca}, \mathrm{K}, \mathrm{Al}, \mathrm{Sr}$ and $\mathrm{Ba}$ ) in vine leaves, Castilla-La Mancha (Spain), Journal of Geochemical Exploration, Vol. 174, 79-83

[4] Davtiana, N.; Ménotb, G.; Barda, E.; Poulenardc, J. \& Podwojewskid P. (2016). Consideration of soil types for the calibration of molecular proxies for soil $\mathrm{pH}$ and temperature using global soil datasets and Vietnamese soil profiles, Organic Geochemistry, Vol. 101, 140-153

[5] Schjønning, P. \& Lamandé, M. (2018). Models for prediction of soil precompression stress from readily available soil properties, Geoderma, Vol. 320, 115-125

[6] Shishkov, T. \& Kolev, N. (2014). The Soils of Bulgaria, Springer Netherlands, ISBN 978-94-007-7784-2

[7] https://www.arduino.cc/

[8] Kadirova, S. (2016). Regulating the moisture of oilseed material in a toaster for vegetable oil extraction, INMATEH - Agricultural Engineering, 3, 99-104. 